\title{
A CIRCULAÇÃO DE IDEIAS REALIZADA POR MEIO DAS ATIVIDADES DE DIVULGAÇÃO CIENTÍFICA EM SALA DE AULA: UM ESTUDO DAS PUBLICAÇÕES EM PERIÓDICOS BRASILEIROS
}

\section{The Circulation of Ideas Carried out Through Scientific Dissemination Activities in the Classroom: A Study of Publications in Brazilian Journals}

\author{
Nara Alinne Nobre-Silva ${ }^{1}$ \\ Roberto Ribeiro da Silva ${ }^{2}$
}

\begin{abstract}
Resumo: Apresentamos um mapeamento das publicações acerca da divulgação científica no período de 2008 a 2018, tendo como objetivo identificar as intencionalidades, as temáticas e os aspectos das práticas pedagógicas que impulsionam a circulação de ideias na sala de aula. A pesquisa de caráter qualitativo, do tipo Análise Documental, foi realizada em quatro fases, abarcando nove periódicos de relevância nacional. 59 artigos foram identificados e classificados em seis diferentes categorias. Entre esses, 17 constituem o corpus da pesquisa e foram submetidos à Análise de Conteúdo. Os resultados apontam que os mesmos estão relacionados à: experiências em sala de aula; interpretações e sentidos que os alunos atribuem aos Textos de Divulgação Científica (TDC); produção e avaliação de materiais didáticos; e utilização dos TDC em atividades de estágios supervisionados. Foi possível também identificar a sala de aula como um espaço favorável à circulação de ideias e que a divulgação científica pode influenciar deslocamentos de sentidos, corroborando para a possível formação de coletivos de pensamento que compartilhem de visões da ciência como uma construção coletiva. Por fim, defendemos que a divulgação científica precisa se fazer presente no espaço escolar desde a educação fundamental, nível em que ocorreu o menor número de intervenções, face ao seu potencial como interface para uma alfabetização científica.
\end{abstract}

Palavras-chave: Divulgação científica. Práticas em sala de aula. Ludwik Fleck. Educação em Ciências.

\footnotetext{
Abstract: We present a mapping of publications about scientific dissemination, from 2008 to 2018, aiming to identify the intentionalities, thematics and aspects of pedagogical practices that drive the circulation of ideas in classrooms. The qualitative research was a Documentary Analysis that carried out in four phases, covering nine journals of national relevance; 59 articles were identified and classified into six different categories. Among these, 17 constitute the research corpus and were submitted to Content Analysis. The results show that they are related to: classroom experiences; interpretations and meanings that students attribute to Scientific

${ }^{1}$ Doutoranda em Educação em Ciências pela Universidade de Brasília. Professora de Química no Instituto Federal de Educação, Ciência e Tecnologia Goiano Campus Iporá. Orcid: https://orcid.org/0000-0002-8964-0519. E-mail: nara.silva@ifgoiano.edu.br.

${ }^{2}$ Doutor em Química pela Universidade Federal de São Carlos. Professor Colaborador Voluntário - Programa de Pós-Graduação em Educação em Ciências, Instituto de Química, Universidade de Brasília. Orcid: https://orcid.org/0000-0003-0805-5594. E-mail: bobsilva@unb.br.
} 
Dissemination Texts (TDC); production and evaluation of teaching materials and the use of TDC in supervised internship activities. It was also possible to identify the classroom as a favorable space for the circulation of ideas and that scientific dissemination can influence displacements of meanings, corroborating for the possible formation of thought collectives that share views of science as a collective construction. Finally, we argue that scientific dissemination needs to be present in the school space since elementary education, the level at which the least number of interventions occurred, given its potential as an interface for scientific literacy.

Keywords: Scientific dissemination. Classroom practices. Ludwik Fleck. Science Education.

\section{Introdução}

As primeiras décadas do século XXI são marcadas pela difusão de uma avalanche de informações, das quais muitas emergem no contexto da desordem informacional. Esta por sua vez, pode ser analisada a partir de duas variáveis: a veracidade ou falsidade da informação e o seu potencial danoso. Não obstante, no campo educacional têm emergido discussões e ações que evidenciam a urgência de que os cidadãos tenham criticidade para avaliar as informações que recebem e consigam refletir e buscar meios para a checagem das mesmas. Por conseguinte, defendemos que o ensino voltado à Alfabetização Científica pode contribuir nesse sentido, ao estimular o pensamento crítico, a argumentação e a tomada de decisão.

Cabe ressaltar, entre os importantes veículos de difusão científica que podem subsidiar processos educativos crítico-reflexivos, a imprensa pedagógica. Esta, por sua vez, é entendida como "uma ramificação da imprensa comum, pois ela é constituída de meios de comunicação (jornais, revistas, outros materiais) que disseminam informações e conhecimentos sobre educação" (RODRIGUES; SILVA, 2014, p. 6). Adiante, Bastos (2007) assinala que o conteúdo circulado pela imprensa cuja ocupação é o ensino e/ou a educação visa guiar a prática dos professores. Logo, ela não é isenta, mas revela posicionamentos de um grupo, de suas formas de compreender e pensar políticas educacionais, práticas pedagógicas, bem como exprime os embates, as disputas e as dissonâncias da área.

Há de se destacar que a trajetória de constituição e fortalecimento da imprensa pedagógica, no Brasil, tem sua gênese no século XIX. Atualmente, ela se perfaz como importante ferramenta para desvelar os modos de funcionamento do campo educacional, especialmente para a historiografia da educação. Soares (2003) indica que, no contexto brasileiro, o periódico "Instrução Pública" foi um dos primeiros voltados à educação e ao ensino. Sob a direção de J. C. de Alambary Luz, foi lançado no dia 13 de abril de 1872. Suas diferentes seções contemplavam assuntos como "questões metodológicas, poesias, história, sobre o ensino de línguas, literatura, ciências" (SOARES, 2003, p. 7), além de noticiário e legislação.

No estado de São Paulo, Catani (1996) aponta a revista "Educação" como uma das primeiras a tentar sistematizar informações a respeito da imprensa periódica educacional. Sua primeira edição, que data de 1929, teve como representante o redator-chefe Carlos da Silveira e como destinatários os professores do estado. Podemos também citar a Revista do Ensino do Estado do Rio Grande do Sul, que teve dois períodos de circulação: o primeiro data de 1939 a 1942 e o segundo, 1951 a 1978. Inicialmente teve centralidade em fornecer sugestões de atividades e planejamentos que orientassem os professores do primário. Posteriormente, contemplou as demais séries do $1^{\circ}$ e $2^{\circ}$ graus (HEIDT, 2018). Trabalhos como o de Pereira (2010) e Heidt (2018) dedicaram-se, respectivamente, a compreender como esta revista se 


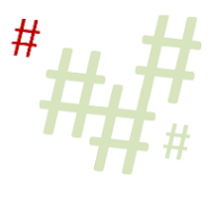

consolidou como produtora de discursos na área da matemática e como as propostas de atividades sugeridas expressavam alinhamento com o escolanovismo.

Com o advento da internet, a imprensa pedagógica se expandiu, e o acesso gratuito a muitos periódicos democratizou o acesso à informação. No que tange à área de Ensino de Ciências, muitas revistas circulam artigos de relatos de experiência e de pesquisas que orientam a prática e o processo de formação inicial e continuada de professores. Entre elas, podemos citar: o Caderno Brasileiro de Ensino de Física, com primeira publicação em 1984; a Química Nova na Escola, criada no ano de 1995; a Revista de Ensino de Biologia da SBEnBio ${ }^{3}$, criada em 2005; a Ensaio, que data de 1993; e a Ciência e Educação, lançada em 1996.

Situada a importância da imprensa pedagógica no campo educacional, tomamos como elemento para discussão a Divulgação Científica. Isto porque ela pode se perfazer como uma estratégia para a promoção da Alfabetização Científica e da almejada formação crítico-reflexiva amplamente defendida no ensino de ciências. Dessa forma, o presente trabalho se orienta pelas seguintes questões: Como a divulgação científica tem sido explorada no contexto da sala de aula? Quais os assuntos têm sido explorados pelos pesquisadores que se dedicam a trabalhar com a divulgação científica? A sala de aula tem se concretizado como espaço de abordagem da divulgação científica?

Nesse contexto, o presente artigo recorre à imprensa pedagógica para apresentar um panorama das publicações relacionadas à divulgação científica em periódicos nacionais, no decorrer da década que compreende os anos de 2008 a 2018. Por desdobramento, temos como objetivo identificar as intencionalidades, as temáticas e os aspectos das práticas pedagógicas que impulsionam a circulação de ideias na sala de aula. Para tanto, utilizamos como referencial teórico Ludwik Fleck.

\section{A divulgação científica e os textos de divulgação científica no ensino de ciências}

A compreensão do conceito que circunda a divulgação científica perpassa, primeiramente, pelo entendimento de difusão científica. Para Bueno (1985), a difusão científica refere-se ao processo ou recurso didático utilizado para a veiculação de informações científicas e tecnológicas. Abrange, assim, os periódicos especializados, reuniões científicas, seções relacionadas ao tema presente em revistas, jornais e outros. Zamboni (2001) acrescenta que na difusão as informações científicas são dirigidas para fora do seu contexto de origem, pois deixam o interior da comunidade científica e chegam ao grande público. Portanto, a difusão engloba a disseminação científica e a divulgação científica (DC). Logo, veicula informações tanto para especialistas como para o público em geral.

A disseminação científica ocorre por meio da veiculação de informações, que utiliza códigos especializados e destina-se a um público seleto composto por especialistas. Ela ocorre em dois níveis: a) intrapares: quando as informações circulam entre os especialistas de uma mesma área ou área conexas; b) extrapares: circulação de informações entre especialistas de outras áreas, mas que possuem conhecimento básico para compreendê-las. O fato é que a disseminação científica, seja em qualquer um dos níveis, restringe-se a um público com conhecimento específico ou com domínio de uma linguagem técnica (BUENO, 1985).

Por outro lado, a divulgação científica é um processo em que a Ciência é traduzida para uma linguagem mais acessível e tem como objetivo a socialização do conhecimento que atinja o grande público (BUENO, 1985). A arte de escrever, utilizando desta linguagem não é recente,

\footnotetext{
${ }^{3}$ SBEnBio: Sociedade Brasileira de Ensino de Biologia.
} 
uma vez que trabalhos que datam dos anos 1624, como o de Galileu, com o livro Diálogo sobre dos máximos sistemas do mundo Ptolomaico e Copérnico, e periódicos como La Science pourfous de 1856 e Science et vie de 1913, ilustram "a preocupação dos pesquisadores no sentido de amenizar o esoterismo do conhecimento científico" (CANEIRO, 2009, p. 1).

Zamboni (2001) indica que a divulgação científica tem uma função educativa, visto que não apenas informa, mas pode contribuir com a formação da opinião pública. Já no âmbito das escolas, embora não haja uma garantia de que exposições, olimpíadas e feiras possam impactar na qualidade da educação científica, elas se concretizam como ações de acessibilidade aos conhecimentos científicos. Outro fator para o uso da divulgação científica consiste na ideia de que ela ajuda a eliminar o misticismo, permitindo, assim, uma representação de mundo mais coerente. Para tanto, é fundamental que a divulgação ocorra no sentido de interação e espaço para o questionamento (CARNEIRO, 2009).

Uma das possibilidades de abordar a divulgação científica em sala de aula ocorre por meio do uso dos Textos de Divulgação Científica (TDC), que se caracterizam por uma linguagem mais flexível, com pouco aprofundamento em detalhes específicos e terminologias mais compreensíveis. Ferreira e Queiroz (2011) indicam que a potencialização dos TDC nas aulas de ciências tem se tornado consenso entre os pesquisadores, pois os mesmos podem contribuir em diferentes aspectos, entre eles: a formação de uma visão da Ciência como um construto humano; aplicações tecnológicas e seus impactos positivos e negativos na sociedade; acesso a informações, assim como o desenvolvimento da capacidade de leitura, interpretação e argumentação.

Ribeiro e Kawamura (2005), na defesa de um processo de ensino que fomente a discussão, as compreensões acerca da natureza do conhecimento científico e as reflexões sobre o contexto social, político, econômico e cultural, propõem um instrumento que permite a seleção de textos de divulgação científica: as dimensões do conteúdo e a forma. Autores como Ferreira e Queiroz (2011), Freire e Massarani (2012), Souza e Rocha (2015) têm se dedicado a analisar os textos publicados em revistas como a Ciência Hoje, a Galileu, a Viver, a Mente e Cérebro, bem como a presença dos mesmos em livros didáticos. Tais pesquisas corroboram com a construção de um quadro que permite caracterizar os veículos de publicação, estimar a confiabilidade dos conceitos científicos informados e facilitar a seleção dos TDC para uso em sala de aula.

\section{Epistemologia fleckiana: a circulação de ideias na divulgação científica}

No que tange à divulgação científica, a epistemologia fleckiana corrobora com elementos teóricos que contribuem para elucidar como a circulação de ideias ocorre entre grupos constituídos por pessoas com níveis diferentes de conhecimento concernentes a um determinado assunto.

Alinhando-nos à proposta de divulgação científica como partilha social do saber e de sua função educativa (ZAMBONI, 2001), apresentamos uma breve descrição sobre o autor desta epistemologia, Ludwik Fleck. Ele nasceu em 1896, na cidade austro-húngara chamada Lemberg, que, após a segunda guerra, passou a se chamar Lwów e pertencer à República Soviética Ucraniana. Formado em medicina, sua carreira científica iniciou-se após a primeira guerra mundial, como assistente em um laboratório cuja especialidade era o tifo e, graças a isto, teve reconhecimento por sua atuação enquanto microbiologista (LOWY, 2012). 

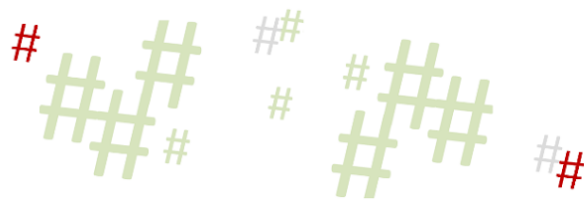

No que se refere às contribuições para a teoria do conhecimento, suas publicações datam do final dos anos 1920 e do ano de 1939, tendo destaque por embutir em suas colocações a dimensão social na construção do conhecimento (FEHR, 2012).

Para compreendermos o fluxo de circulação de ideias proposto por Fleck, precisamos, inicialmente, entender que, quando um grupo de pessoas compartilha um mesmo estilo de pensamento, isto é, as mesmas concepções, crenças, conhecimentos e formas de pensar sobre um determinado objeto, elas constituem um coletivo de pensamento. Um coletivo de pensamento se organiza em círculos concêntricos, denominados esotéricos e exotéricos. $\mathrm{O}$ primeiro é constituído por especialistas em um determinado assunto, e o segundo por leigos ou leigos formados.

No contexto superestruturante da divulgação científica, os jornalistas e cientistas constituem o círculo esotérico, pois são os responsáveis por transformar o conteúdo a ser divulgado em uma linguagem menos especializada e codificada, enquanto o público em geral compõe o círculo exotérico. No contexto estruturante, observamos que ao falarmos de ciências específicas, os próprios jornalistas e cientistas podem em algum momento compor o círculo exotérico. Por exemplo, para a produção de um texto de divulgação científica sobre eletricidade estática é preciso recorrer a conceitos científicos de domínio de cientistas físicos, que não são, necessariamente, de domínio de cientistas geógrafos. Logo, os cientistas que dominam a linguagem técnica do assunto em estudo participam do círculo esotérico e os que não a dominam compõem o círculo exotérico junto à população geral.

A existência desses círculos pressupõe a coexistência de grupos com diferentes níveis de conhecimento, o que fomenta a interação entre eles. Essa interação se estabelece a partir do que Fleck denomina circulação de ideias, seja de forma intracoletiva ou intercoletiva. A intracoletiva é a que ocorre entre os especialistas (jornalistas e cientistas), sendo caracterizada por um discurso com terminologias específicas, linguagem técnica e maior aprofundamento teórico; já a intercoletiva ocorre entre os círculos esotérico e exotérico. Nesta dinâmica, os especialistas apresentam o conhecimento para o público leigo e este, ao acessá-lo, o avalia, ressignifica e o retorna aos especialistas.

É por meio da circulação intercoletiva que ocorre a extensão ou mudança do estilo de pensamento. Para que haja esta mudança é preciso que:

a) o indivíduo compreenda as limitações do seu estilo de pensamento em relação ao objeto em estudo ou a realidade exposta, isto é, as complicações existentes. A complicação é o período em que os problemas não podem ser mais respondidos pelas teorias vigentes, daí emerge a necessidade de um novo modo de agir e de pensar (LAMBACH, 2007), que são os "questionamentos que surgem a partir das explicações insuficientes dadas aos fenômenos" (LAMBACH; MARQUES, 2014, p. 87);

b) haja uma relação de confiança no círculo esotérico. Para que o público leigo se aproprie dos conhecimentos veiculados pelos diferentes meios (jornais, revistas, programas de TV) e, por conseguinte, mude ou transforme sua forma de pensar em relação a determinado fato, é preciso ter confiança na equipe responsável pela veiculação daquela informação. Exemplificando, quando sabemos que um determinado programa ou jornal é tendencioso a uma corrente de pensamento não aceita socialmente por um grupo, é possível que, ao ler o material por ele veiculado, haja uma resistência em aceitar as informações apresentadas.

Fleck esclarece que, ao circular entre os indivíduos, o pensamento passa por um processo de modificação, visto que cada indivíduo o associa às suas próprias ideias. Acrescenta que "a rigor, o receptor nunca entende um pensamento da maneira como o emissor quer que 
seja entendido" (FLECK, 2010, p. 85), uma vez que passa por deformações, deixa de conter o conteúdo original, o que não impede sua circulação, pois deixa de ser individual e passa a ser um pensamento coletivo. Sob esta ótica, a análise das ideias contidas em uma produção textual pode não representar fidedignamente o real, pois a interpretação do receptor está permeada de conceitos anteriores; logo, não é neutra. Por outro lado, investigações como as de Gonçalves e Marques (2012), que se dedicaram a estudar a circulação inter e intracoletiva de ideias por meio de pesquisas e publicações, podem contribuir para traçar estratégias que favoreçam e otimizem a interação entre os diferentes círculos, bem como indicar os assuntos mais discutidos e os que podem ser explorados.

\section{Delineamentos metodológicos}

A presente investigação segue os pressupostos da pesquisa qualitativa, com ênfase nos aspectos descritivos e seus desdobramentos. Conforme Flick (2009), não há um conceito teórico metodológico unificado para sintetizar o que se entende por pesquisa qualitativa, mas há de se aceitar que os pontos de vista subjetivos e a pluralidade metodológica perpassam sua explicação. Dessa forma, imbricados pelos aspectos citados, o levantamento deste trabalho seguiu as quatro fases da Análise Documental, proposta por Rosa (2013): 1) Definição das palavras-chaves: utilizamos os descritores "divulgação científica" e, posteriormente, acrescentado o termo "divulgação da ciência"; 2) Definição do escopo: periódicos da área de ensino de ciências; 3) Seleção do corpus: trabalhos que remetiam às experiências em sala de aula; 4) Análise.

A busca foi realizada em nove periódicos de relevância nacional, de grande circulação entre os pesquisadores, professores e alunos da área de ensino de ciências e de acesso on-line gratuito. O Quadro 1 indica os periódicos selecionados, o Qualis Capes da área de ensino (20132016) e a respectiva quantidade de artigos localizados. Priorizamos como intervalo a década que compreende os anos de 2008 a 2018, por consistir em um período significativo para delinear a produção referente a um objeto de estudo. Ademais, o corpus identificado nesse intervalo apresenta artigos com pluralidades temáticas que fundamentam nossas análises e interpretações.

Quadro 1- Número de artigos localizados por periódicos.

\begin{tabular}{|c|c|c|}
\hline Periódico & Qualis & $\begin{array}{c}\mathrm{N}^{\circ} \text { de artigos } \\
\text { localizados }\end{array}$ \\
\hline Alexandria & $\mathrm{A} 2$ & 13 \\
\hline Ciência e Educação & A1 & 19 \\
\hline Ciência e Ensino & B1 & 2 \\
\hline Ensaio - Pesquisa em Educação em Ciências (Ensaio) & A1 & 6 \\
\hline Investigações em Ensino de Ciências (IECI) & $\mathrm{A} 2$ & 4 \\
\hline Química Nova na Escola (QNEsc) & B1 & 5 \\
\hline Revista Brasileira de Ensino de Química (REBEQ) & B2 & 1 \\
\hline Revista de Ensino de Ciências e Matemática (ReCiMa) & A2 & 3 \\
\hline $\begin{array}{l}\text { 9. Revista Electrónica de Enseñanza de las Ciencias } \\
\text { (REEC) }\end{array}$ & A2 & 6 \\
\hline
\end{tabular}

Fonte: Elaborado pelos autores, 2020.

No total, foram localizados 59 artigos, que após a leitura flutuante foram classificados de acordo com as seis categorias a seguir. 
a) Experiências em sala de aula: referem-se às práticas desenvolvidas no espaço formal de ensino.

b) Experiências em espaços não-formais: compreendem atividades realizadas com alunos em museu e casa da ciência.

c) Teóricos ou revisão bibliográfica: discutem as publicações científicas em periódicos e livros.

d) Análise de jornais, revistas, programas de TV ou filmes: dedicam a analisar textos e/ou discursos propagados pelos diferentes veículos midiáticos.

e) Formação continuada de professores: apresentam propostas teóricas ou resultados de pesquisas empíricas realizadas na formação continuada de professores.

f) Análise do discurso de cientistas/professores: o foco é o discurso apresentado por cientistas/professores em palestras e espaços de visita, como museus e centro de ciências.

A Tabela 1 indica a distribuição dos artigos de cada periódico por categoria.

Tabela 1- Quantitativo de artigos por categoria de análise.

\begin{tabular}{lcccccc}
\hline \multicolumn{1}{c}{ Periódico } & I & II & III & IV & V & VI \\
Alexandria & 3 & 0 & 1 & 7 & 1 & 1 \\
$\begin{array}{l}\text { Ciência e Educação } \\
\text { (C.E) }\end{array}$ & 4 & 2 & 1 & 9 & 1 & 2 \\
Ciência e Ensino & 1 & 0 & 0 & 1 & 0 & 0 \\
Ensaio & 2 & 0 & 0 & 2 & 0 & 2 \\
IECI & 1 & 0 & 2 & 1 & 0 & 0 \\
QNEsc & 1 & 0 & 2 & 0 & 0 & 2 \\
REBEQ & 1 & 0 & 0 & 0 & 0 & 0 \\
ReCiMa & 1 & 0 & 0 & 0 & 0 & 2 \\
REEC & 3 & 0 & 0 & 3 & 0 & 0 \\
\hline Total & 17 & 2 & 6 & 23 & 2 & 9 \\
\hline
\end{tabular}

Para a última fase proposta por Rosa (2013), selecionamos apenas os 17 artigos enquadrados na categoria I (Experiências em sala de aula). Os artigos selecionados foram submetidos à Análise de Conteúdo, emergindo categorias que tratam das áreas de conhecimento, das temáticas e dos aspectos das práticas pedagógicas que fomentam a circulação de ideias no âmbito da sala de aula. Adiante, reflexões foram inspiradas resultando na inferência de conhecimentos (BARDIN, 2016).

\section{A divulgação científica no contexto da sala de aula: caracterização das publicações}

Com a intenção de compreender como a divulgação científica tem sido explorada no contexto da sala de aula, foi realizada uma leitura minuciosa dos 17 artigos pertencentes a categoria I (Experiências em sala de aula), indicados pelo Quadro 2. Os códigos atribuídos a cada artigo foram formados a partir de números crescentes (1 a 17) acrescentados das iniciais do periódico de origem. A sequência dos periódicos apresentada no Quadro foi aleatória. 
Quadro 2 - Título dos artigos selecionados.

\begin{tabular}{|c|c|c|c|}
\hline \multicolumn{2}{|c|}{ Código } & Título do artigo & \multirow{2}{*}{$\begin{array}{c}\begin{array}{c}\text { Ano da } \\
\text { publicação }\end{array} \\
2012 \\
\end{array}$} \\
\hline \multirow{3}{*}{$\begin{array}{l}\text { Alex } \\
\text { andr } \\
\text { ia }\end{array}$} & 01AL & $\begin{array}{l}\text { Textos de Divulgação Científica na formação inicial de } \\
\text { professores de química }\end{array}$ & \\
\hline & 02AL & $\begin{array}{l}\text { A leitura por alunos do ensino médio de um texto considerado de } \\
\text { alto grau de dificuldade }\end{array}$ & 2014 \\
\hline & $03 \mathrm{AL}$ & $\begin{array}{l}\text { A utilização de uma história em quadrinhos como estratégia de } \\
\text { ensino sobre uso racional de medicamentos }\end{array}$ & 2016 \\
\hline \multirow{3}{*}{$\begin{array}{l}\text { REE } \\
\text { C }\end{array}$} & 04RE & $\begin{array}{l}\text { Leitura de divulgação científica por licenciandos em ciências } \\
\text { biológicas }\end{array}$ & 2009 \\
\hline & 05RE & $\begin{array}{l}\text { Uma história em quadrinhos para o ensino de divulgação da } \\
\text { hanseníase }\end{array}$ & 2010 \\
\hline & 06RE & $\begin{array}{l}\text { Ressonância magnética: leitura e mediação do professor no ensino } \\
\text { médio }\end{array}$ & 2014 \\
\hline \multirow{2}{*}{$\begin{array}{l}\text { Ensa } \\
\text { io }\end{array}$} & 07EN & $\begin{array}{l}\text { A repetição em interpretações de licenciandos em física ao lerem } \\
\text { as revistas Ciência Hoje e Pesquisa Fapesp }\end{array}$ & 2010 \\
\hline & 08EN & $\begin{array}{l}\text { Leitura de um texto de divulgação científica em uma disciplina de } \\
\text { física básica na educação superior }\end{array}$ & 2013 \\
\hline \multirow{4}{*}{ C.E } & 09CEd & $\begin{array}{l}\text { Autoria no ensino de química: análise de textos escritos por alunos } \\
\text { de graduação }\end{array}$ & 2011 \\
\hline & 10CEd & $\begin{array}{l}\text { Kit paleontológico: um material didático com abordagem } \\
\text { investigativa }\end{array}$ & 2014 \\
\hline & 11CEd & $\begin{array}{l}\text { Leitura por alunos do ensino médio de textos de cientistas sobre o } \\
\text { início da física quântica }\end{array}$ & 2016 \\
\hline & 12CEd & $\begin{array}{l}\text { Leitura e argumentação: potencialidades do uso de textos de } \\
\text { divulgação científica em aulas de Física do ensino médio }\end{array}$ & 2017 \\
\hline IECI & 13IE & $\begin{array}{l}\text { Leitura de textos de ciências de diferentes gêneros: um olhar } \\
\text { cognitivo-processual }\end{array}$ & 2010 \\
\hline $\begin{array}{l}\text { QNE } \\
\text { sc }\end{array}$ & $14 \mathrm{QN}$ & $\begin{array}{l}\text { Elaboração de textos de divulgação científica e sua avaliação por } \\
\text { alunos de licenciatura em química }\end{array}$ & 2016 \\
\hline $\begin{array}{l}\text { REC } \\
\text { iMa }\end{array}$ & $15 \mathrm{RC}$ & $\begin{array}{l}\text { O jornal "A física de ontem e hoje" como instrumento de } \\
\text { divulgação e discussão científica dentro e fora do ambiente escolar }\end{array}$ & 2017 \\
\hline $\begin{array}{c}\text { ReB } \\
\text { EQ }\end{array}$ & 16RB & $\begin{array}{l}\text { Textos de divulgação científica: uma possibilidade para superar a } \\
\text { fragmentação do conhecimento e as concepções de alunos do } \\
\text { ensino médio em aulas de química }\end{array}$ & 2015 \\
\hline $\begin{array}{c}\text { Ciên } \\
\text { cia e } \\
\text { Ensi } \\
\text { no }\end{array}$ & 17CEn & $\begin{array}{l}\text { O estágio curricular supervisionado em química como espaço para } \\
\text { o desenvolvimento de atividades didáticas pautadas no uso de } \\
\text { textos de divulgação científica }\end{array}$ & 2014 \\
\hline
\end{tabular}

Fonte: Elaborado pelos autores, 2020.

A Figura 1 apresenta o quantitativo de pesquisas realizadas por nível de ensino: fundamental, médio e superior.

Destacamos que os trabalhos que envolveram alunos do ensino superior (licenciandos) desenvolvendo atividades no ensino médio e/ou fundamental ocorreram por meio dos estágios supervisionados. O assunto de divulgação científica foi primeiro discutido pelos professores dos licenciandos nas disciplinas dos cursos aos quais estavam vinculados e, posteriormente, os materiais preparados (TDC) foram utilizados nas aulas de regência no ensino médio. Possivelmente, há um coletivo de pensamento formado/em formação pelos professores do 
ensino superior e seus alunos, que compartilharam da importância da veiculação de informações científicas em uma linguagem mais acessível ao público geral. Além disso, estas práticas vão ao encontro das propostas de Gomes, Silva e Machado (2016), que ressaltam a necessidade de as disciplinas de estágio supervisionado valorizarem a produção e utilização dos TDC no plano de aula da regência.

Figura 1- Nível de ensino em que, durante a pesquisa, a DC foi promovida.

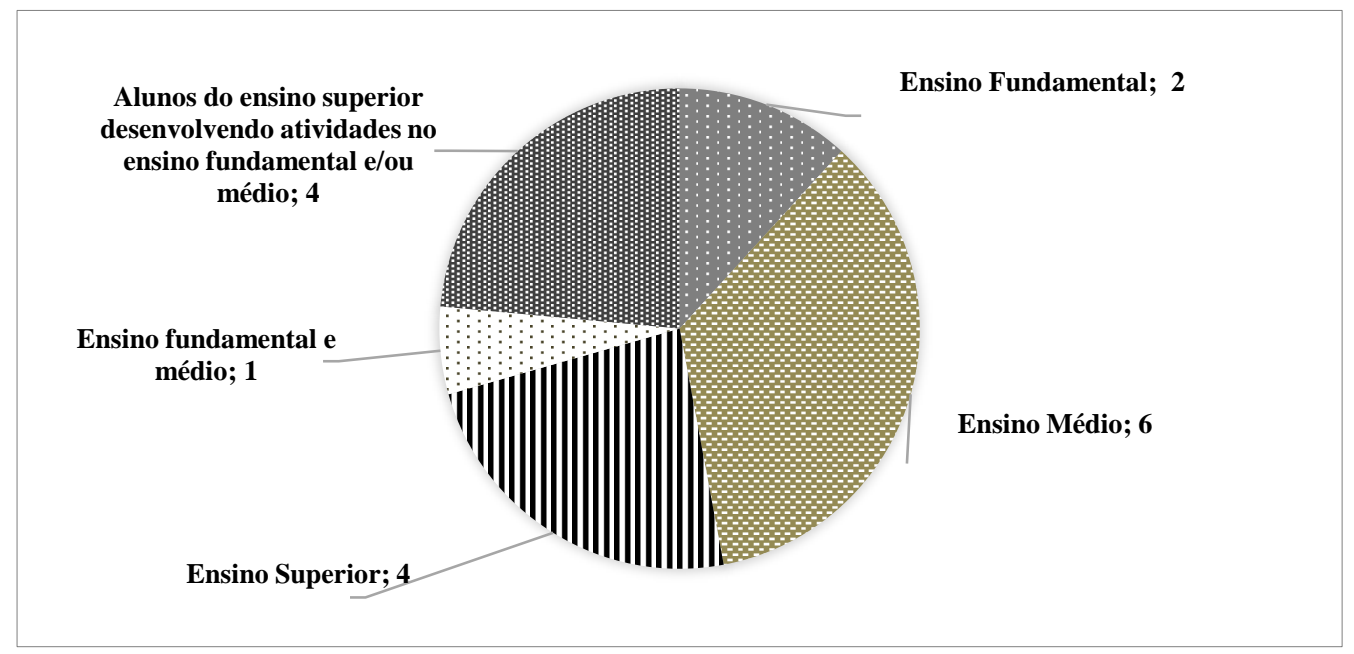

Fonte: Elaborado pelos autores, 2020.

No ensino fundamental, o número de propostas desenvolvidas totaliza 04 (04RE, 05RE, 10CEd, 13IE), enquanto no ensino médio, 11 (01AL, 02AL, 03AL, 04RE, 06RE, 11CEd, $12 \mathrm{CEd}, 13 \mathrm{IE}, 15 \mathrm{RC}, 16 \mathrm{RB}, 17 \mathrm{CEn}$ ). Isto pode estar relacionado a diversos fatores, por exemplo, maior incidência de pesquisas acerca do ensino de ciências no nível médio, as disciplinas da área de Ciências da Natureza, como Biologia, Química e Física, são estudadas com mais ênfase na última etapa da educação básica. Por outro lado, os assuntos científicos e tecnológicos veiculados pelos materiais de divulgação científica (revistas, jornais, livros) são associados mais facilmente aos conteúdos curriculares propostos para o ensino médio. Contudo, considerando o potencial da divulgação científica tanto para a informação, como para o desenvolvimento do pensamento crítico, da leitura e da argumentação (FERREIRA; QUEIROZ, 2011), ressaltamos a necessidade de que a mesma seja promovida para o público de toda a educação básica, do ensino superior e da pós-graduação.

Para analisar, nos trabalhos, o movimento de circulação de ideias por meio da divulgação científica, elaboramos três eixos: I) Intencionalidades; II) Material utilizado, e III) Temáticas centrais, os quais são indicados nas seções a seguir.

\subsection{Eixo I - Intencionalidades}

No que tange às intencionalidades, houve o desdobramento nas seguintes categorias: a) Investigar o interesse dos alunos pelos TDC; b) Interpretação ou sentidos atribuídos ao texto; c) Avaliação do uso de TDC em sala de aula; d) Elaboração e aplicação de material didático. Segue, abaixo, a discussão de cada uma:

a) Investigar o interesse dos alunos pelos TDC: concentra os trabalhos que têm como objetivo analisar os aspectos que influenciam o gosto por um TDC. Pertence a esta categoria apenas o artigo 02AL, cuja intenção dos autores incide em compreender se o interesse pela 
leitura dos alunos do ensino médio por um TDC está mais associado ao assunto do texto ou ao tipo de linguagem com que foi produzido. Uma análise a partir de Orlandi (2005), que considera os tipos de repetições (empírica, formal e histórica), apontou que, embora o tema fosse de interesse de grande parte da turma, a linguagem complexa dificultou a interpretação, tornando o texto pouco acessível.

b) Interpretação ou sentidos atribuídos ao texto: busca identificar como os alunos, ao entrarem em contato com os TDC, produzem sentidos ou os interpretam. Os referenciais mais utilizados foram: o conceito de leitura e as interpretações assumidas pelo sujeito; autoria e repetição (empírica, formal e histórica) propostas por Orlandi (1983, 1988, 1994, 1996, 1998, 2005, 2012); a síntese de ideias (SOLÉ, 1998); a concepção autoritária (KLEIMAN, 2007) e as compreensões do discurso de Van Dijk e Kintsch (1983). Fazem parte desta categoria: 04RE, 06RE, 07EN, 09CEd, 11CEd, 12CEd, 13IE, 17CEn.

Nascimento e Rezende Junior (2010), ao mapearem a produção relativa à divulgação científica na área de Ensino de Ciências (anais, periódicos e teses), também identificaram uma significativa quantidade de trabalhos que discorriam sobre a leitura e produção de sentidos por estudantes a partir dos TDC. Portanto, consideramos que este referencial pode possibilitar aos professores compreenderem como seus alunos ressignificam os textos utilizados em situações de ensino e, assim, levá-los a direcionamentos que conduzam a um processo de aprendizagem mais efetivo.

c) Avaliação do uso de TDC em sala de aula: tem como objetivo identificar como o TDC pode ser utilizado em situações de ensino, os sentidos atribuídos às estratégias recorridas para utilizá-los e as concepções dos alunos sobre o uso dos mesmos. Estão contemplados nesta categoria os trabalhos $01 \mathrm{AL}, 08 \mathrm{EN}$ e $16 \mathrm{RB}$, cujos participantes são, respectivamente, alunos do ensino superior que desenvolveram atividade de regência no ensino médio; alunos do ensino superior; e alunos do ensino médio. Os referenciais mais presentes foram de Orlandi (1988, 2002), a fim de compreender os modos de funcionamento do discurso, que se distinguiram em discurso autoritário, discurso polêmico e discurso lúdico; as possibilidades de repetição (empírica, formal e histórica); e Salém e Kawamura (1996) com a importância de tornar os conhecimentos científicos acessíveis.

Os resultados apontaram que os TDC contribuem para menor fragmentação dos conhecimentos científicos, permitem introduzir aspectos da história da ciência e as implicações sociais, de que a potencialidade dos textos está associada à estratégia didática escolhida pelo professor. Por fim, indicam a mediação prévia com os TDC e posterior abordagem dos conteúdos como forma mais eficaz à apropriação de conhecimentos.

d) Elaboração e aplicação de material didático: englobam os trabalhos que discorrem a respeito do processo de criação e aplicação de materiais, como história em quadrinhos, folhetos, textos e jornais, e foram agrupados nesta categoria os artigos 03AL, 05RE, 10CEn, 14QN e 15RC. Todos os materiais construídos apresentaram características positivas, constituindo-se como alternativas motivadoras, interessantes e com linguagem acessível. Além disso, o trabalho 05RE destaca-se pelo uso de uma história em quadrinhos para veicular informações corretas sobre a hanseníase. O 14QN, por construir TDC com propósito educacional, fundamentou-se em eixos norteadores como a experimentação e a natureza da ciência. Conforme já ressaltado por Terrazan e Gabana (2003), os TDC produzidos por jornalistas e cientistas não possuem função primeira de ensinar conceitos científicos e podem apresentar informações distorcidas. Por outro lado, consideramos que, quando elaborados por professores e alunos, há uma maior possibilidade de que os mesmos tenham características próprias para uso no ensino 
Por último, o 15RC trata-se da difusão científica por meio de um jornal, utilizado em sala de aula, que depois foi distribuído gratuitamente em uma banca de jornal e fixado no mural da escola. Tal ação democratizou o acesso à informação não apenas no espaço formal de ensino, mas estendeu-o à comunidade.

\subsection{Eixo II - Material utilizado}

Entre as 17 propostas desenvolvidas, os materiais que mais se destacaram foram os TDC, sejam os provenientes de revistas, livros ou de produção própria, seguido pelas histórias em quadrinhos (HQ) e o folheto. O Quadro 3 apresenta um panorama de como estes materiais foram utilizados nos diferentes níveis de ensino. Alguns trabalhos estão localizados em mais de uma coluna, pois sua metodologia corresponde ao uso de mais de um tipo de material. Também houve casos em que os mesmos recursos foram utilizados em níveis de ensino diferentes.

Quadro 3- Tipo de material usado em cada trabalho e respectivos níveis de ensino em que a propostas foram desenvolvidas.

\begin{tabular}{|c|l|l|l|l|l|l|l|}
\hline $\begin{array}{c}\text { Nível de } \\
\text { ensino }\end{array}$ & $\begin{array}{c}\text { TDC } \\
\text { autoria } \\
\text { própria }\end{array}$ & $\begin{array}{c}\text { TDC de } \\
\text { revistas }\end{array}$ & $\begin{array}{c}\text { TDC de } \\
\text { Livros }\end{array}$ & HQ & Folheto & Jornal & $\begin{array}{c}\text { TDC fonte } \\
\text { não } \\
\text { indicada }\end{array}$ \\
\hline Fund. & $04 \mathrm{RE}$ & $04 \mathrm{RE}$ & & $05 \mathrm{RE}$ & $10 \mathrm{CEd}$ & $04 \mathrm{RE}$ & $13 \mathrm{IE}$ \\
\hline & $\begin{array}{l}03 \mathrm{AL} \\
04 \mathrm{RE}\end{array}$ & $\begin{array}{l}01 \mathrm{AL} \\
02 \mathrm{AL} \\
04 \mathrm{RE} \\
06 \mathrm{RE} \\
12 \mathrm{CEd} \\
16 \mathrm{RB}\end{array}$ & $\begin{array}{l}11 \mathrm{CEd} \\
17 \mathrm{CEn}\end{array}$ & $03 \mathrm{AL}$ & & & \\
\hline Médio & $15 \mathrm{RC}$ & $07 \mathrm{EN}$ & $08 \mathrm{EN}$ \\
& $14 \mathrm{QN}$ & & & & & & \\
\hline $\begin{array}{c}\text { Superio } \\
\mathrm{r}\end{array}$ & & & & & & & \\
\hline
\end{tabular}

Fonte: Elaborado pelos autores, 2020.

Os TDC de revistas foram os mais utilizados pelos pesquisadores, seguidos pelos textos de elaboração própria. Voltamos a destacar o potencial de os professores e alunos produzirem os próprios textos que serão utilizados em suas aulas/regências, pois há uma maior possibilidade de que a transposição de conhecimentos científicos ocorra de maneira adequada. Ademais, de que a linguagem e tratamento do assunto sejam compatíveis com o nível de ensino.

Dentre as revistas utilizadas para a extração dos TDC, foram citadas as: Ciência Hoje (02AL, 06RE, 07EN, 12CEd), Pesquisa Fapesp (01AL, 07EN), Química Nova na Escola (16RB), Scientific American Brasil (12CEd), o Estado de São Paulo (12CEd) e a Nova Escola (04RE), assemelhando-se com os resultados do mapeamento realizado por Nascimento e Rezende Junior (2010). Acreditamos que a revista Ciência Hoje tem se destacado pela sua função efetiva na popularização da ciência, pela qualidade dos textos e pela abordagem ampla e aprofundada, com o uso de recursos como imagens e boxes, que são atraentes ao público leigo.

A revista Ciência Hoje tem se protagonizado como objeto de pesquisa em vários trabalhos, a citar: Costa (2016), que discorre acerca das relações entre discurso e ideologia, a partir das ideias do Círculo de Baktin; Ferreira e Queiroz (2011), que investigaram o potencial didático e; Goldbach e El-Hani (2008), que exploraram a presença de analogias e ideias sobre 
genes. Em relação aos livros, foram citados "A dança do universo" (GLEISER, 1997), "Tio Tungstênio: memórias de uma infância química" (SACKS, 2002), "O sonho de Mendeleev" (STRATHERN, 2002), "O universo sem mistério" (FERREIRA, 2003) e" Autobiografia científica e outros ensaios" (PLANCK, 2012). O Quadro 4 indica os textos utilizados em cada trabalho.

Quadro 4 - Textos de livros utilizados pelos trabalhos.

\begin{tabular}{|c|c|c|}
\hline Autor & Capítulos & Artigos \\
\hline GLEISER, 1997 & O mundo é uma máquina complicada & 8EN \\
\hline SACKS, 2012 & Luz brilhante e O jardim de Mendeleev & 9CEd \\
\hline $\begin{array}{c}\text { STRATHERN, } \\
20002\end{array}$ & $\begin{array}{c}\text { As tríades de Dobereiner, O parafuso telúrico de } \\
\text { Chancourtois, As oitavas de Newlands, Algo sobre } \\
\text { Mendeleev, A persistência de Mendeleev }\end{array}$ & $17 \mathrm{CEn}$ \\
\hline FERREIRA, 2003 & $\begin{array}{c}\text { Física Quântica: o estranho comportamento do mundo } \\
\text { microscópico }\end{array}$ & $11 \mathrm{CEd}$ \\
\hline PLANCK, 2012 & Novas vias de acesso aos conhecimentos da física & $11 \mathrm{CEd}$ \\
\hline
\end{tabular}

\subsection{Eixo III- Temáticas centrais}

Para discutir as temáticas centrais, utilizamos como eixo norteador a área de Ciências da Natureza, desdobrando-se nas categorias: a) Ciências, b) Biologia, c) Física e d) Química. Em alguns trabalhos a área estava explícita, em outros o agrupamento ocorreu pela aproximação dos conteúdos/assuntos mencionados. A Figura 2 indica o quantitativo de trabalhos vinculados a cada uma das categorias.

Figura 2 - Áreas contempladas nos trabalhos

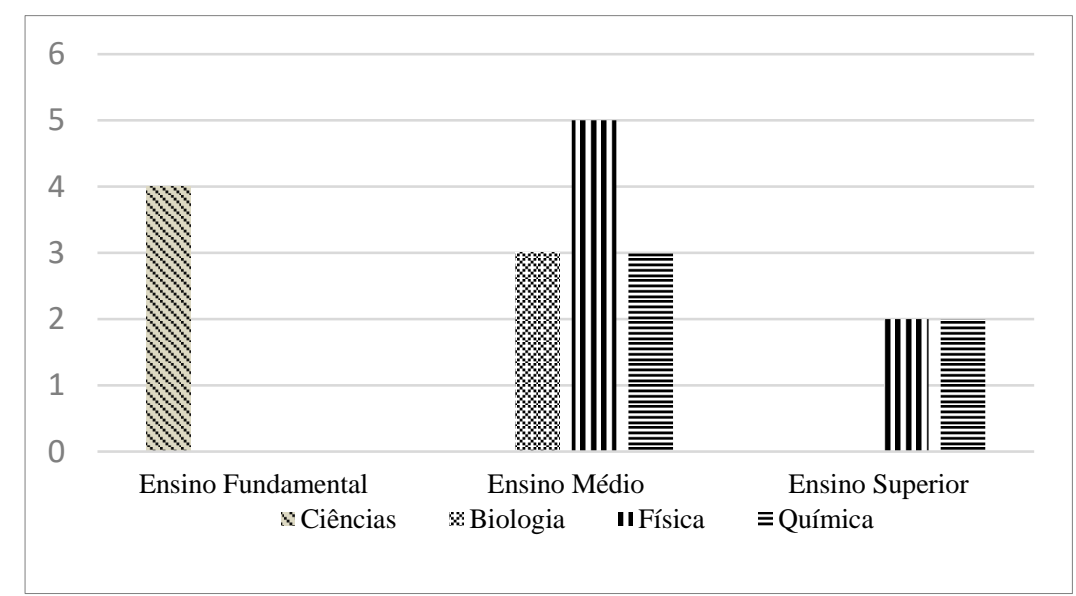

Fonte: Elaborado pelos autores, 2020.

a) Ciências

Pertencem a esta categoria os trabalhos: 04RE, 05RE, 10CEd e 13IE, cujos assuntos abordados foram: água, hanseníase, fósseis, rochas, bacias sedimentares e anemia falciforme. No geral, observamos uma preocupação em disseminar informações sobre doenças, formas de transmissão e de tratamento. Estas ações são salutares por permitir esclarecimentos e contribuir para a conscientização e mudança de postura. Além disso, "Saúde" é um tema transversal e deve ser articulado em todos os níveis de ensino, por todas as disciplinas do currículo, com intuito de promover uma aprendizagem efetiva e transformadora de hábitos e atitudes. 
As estratégias de ensino utilizadas pelos autores foram bem diversificadas. Por exemplo, leitura de manchetes de jornais, exibição de vídeos, desenvolvimento de aulas experimentais com auxílio de folhetos, leitura e discussão de TDC. Observamos uma preocupação em utilizar estratégias que estimulassem a participação dos alunos e interligassem os saberes apreendidos na escola com os do cotidiano.

b) Biologia

Nessa área, concentraram-se três trabalhos efetivados no ensino médio: 03AL, 04RE, 13IE, que foram publicados, respectivamente, nos anos de 2016, 2009 e 2010. Observamos uma carência de ações nesta área, com baixa representação no ensino médio e no ensino superior. Os assuntos contemplados foram: automedicação, intoxicação alimentar, sistema sanguíneo, ecologia e anemia falciforme, com a utilização de história em quadrinhos, vídeos, leitura e discussão dos textos. A divulgação científica foi abordada com intuito de aguçar a curiosidade dos jovens a respeito de temas relacionados às Ciências da Saúde e Ciências Sociais e estimular a leitura. Os autores concluíram que apresentaram maior sucesso nos estudos os alunos que utilizaram os TDC, já que construíram representações mais completas das situações, e que os TDC funcionam bem quando passam pelas mediações dos professores/ regentes.

c) Física

Esta categoria é formada pelo maior número de trabalhos, 7 no total, dos quais 2 referem-se ao ensino superior (07EN, 08EN) e 5 ao ensino médio (02AL, 06RE, 11CEd, $12 \mathrm{CEd}, 15 \mathrm{RC})$. Embora a representatividade desta área seja maior, em relação às demais, não podemos dizer que houve uma expansão da área no cenário brasileiro, pois dos 7 trabalhos publicados, 5 são vinculados a autores de uma mesma instituição.

Entre os assuntos que permearam as propostas, podemos citar: história e aplicações da ressonância nuclear magnética; avanços tecnológicos decorrentes da física quântica; radiação eletromagnética; temperatura; natureza da luz; calorias; critérios a se considerar ao comprar um carro; eficácia do etanol e da gasolina; ondas sonoras e critérios para a escolha de um bom fone de ouvido; evolução dos meios de comunicação; eletricidade; iluminação e cientistas brasileiros como César Lattes.

Observamos uma preocupação não apenas de contemplar conteúdos curriculares, mas de apoiar-se a divulgação científica no sentido de uma alfabetização científica, que permite aos alunos avaliarem diferentes situações e fenômenos do dia-a-dia e, assim, escolherem, de forma consciente, o que pode lhes beneficiar ou trazer menos impacto. Por conseguinte, os conteúdos são trabalhados a partir de uma perspectiva de historicidade, indicando que a tecnologia que possuímos hoje tem uma origem, que passou e passa por influências.

As estratégias mais recorridas nos trabalhos foram: a) leitura individual por parte dos alunos, sem a mediação do professor e depois com a mediação do professor para esclarecer as dúvidas expressas pelos alunos, quando o interesse dos pesquisadores era compreender as interpretações e os sentidos atribuídos ao texto; b) questões iniciais para identificar os conhecimentos prévios ou identificar assuntos de interesse da turma; leitura individual e identificação de trechos importantes; elaboração de questões, a partir dos TDC; produção de resumo e propagandas; distribuição de jornais à comunidade interna e externa, quando o interesse era desenvolver a capacidade de interpretação, compreensão e argumentação para aproximar a população de temas científicos e a difusão da ciência. 
d) Química

Estimular a compreensão em sala de aula, favorecer a capacidade de interpretação de textos, ressignificar a ciência, esclarecer fenômenos do dia-a-dia, que propiciam práticas interdisciplinares e minimizar a fragmentação dos conteúdos constituíram os principais objetivos dos pesquisadores que utilizaram a DC no contexto das aulas de Química. Representam esta categoria os artigos: 01AL, 09CEd, 14QN, 16RB e 17CEn.

Dois dos artigos citados referem-se a situações de ensino, envolvendo alunos da graduação. No primeiro (14QN), os alunos avaliaram os TDC produzidos por seus professores, considerando os aspectos da relação fenômeno-teoria, da natureza do conhecimento científico, da história da ciência, dos aspectos CTSA, das relações éticas de consumo e cidadania e os aspectos interdisciplinares. No segundo (09CEd), os próprios alunos produziram textos a partir da leitura de capítulos do livro "Tio Tungstênio: memórias de uma infância química".

Em ambos os casos, os protagonistas eram alunos de cursos de Licenciatura, o que indica preocupação de seus professores em inserir a divulgação científica no contexto da formação inicial e de que essa vivência contribua tanto no processo cognitivo como em suas futuras práticas profissionais. Concordamos com Ferreira e Queiroz (2012, p.19-20) que estas ações junto à formação inicial "representam caminhos para que os professores em formação tomem conhecimento da existência e das possibilidades de uso didático do TDC, que poderão resultar em práticas diferenciadas nas salas de aula nas quais atuarão".

Já os artigos 01AL e 17CEn são situações de ensino em que alunos da graduação, ao desenvolverem seus estágios supervisionados em turmas do ensino médio, utilizaram-se de TDC. Mais uma vez, ressaltamos o potencial desta proposta, pois os graduandos tiveram apoio de seus professores no planejamento das atividades, escolha e escrita de seus textos, e, posteriormente, os mesmos realizaram suas regências.

Os artigos indicaram que os licenciandos, por meio da regência, aproximaram-se de um recurso pouco explorado (uso de TDC) e entenderam que suas potencialidades estão condicionadas às suas decisões pedagógicas. A partir daí, reelaboraram os TDC influenciados por suas histórias de leitura e os imaginários: o que é ser professor, o que é ensino aprendizagem e o que é Ciência. Adiante, os TDC assumiram funções importantes, como despertar o interesse dos alunos e promover a contextualização dos conteúdos.

Por fim, o artigo 16RB buscou entender as concepções de 20 alunos do ensino médio sobre os TDC e sua importância para a sociedade. A metodologia e as discussões apresentamse como primárias, cujas considerações foram:

os resultados alcançados neste trabalho demonstraram que os TDC podem ser utilizados como estratégia para o Ensino de Química, uma vez que essa estratégia é interessante e diferenciada, fugindo da aula tradicional e contribuindo para a não fragmentação do saber [...]. (PRYSBYCIEM et al., 2015, p.77).

Os temas mais recorridos ao utilizar TDC foram: processo de fabricação de fibras acrílicas, a importância da química para a sociedade, o que é a química e o que o químico faz, a produção do conhecimento científico, história de cientistas como Rutheford, as descobertas de Moseley, investigações criminais, alimentos, metais e água. Entre as estratégias utilizadas, destacaram-se a leitura e preenchimento de questionários/questões livres, quando a intenção era que o aluno avaliasse o TDC ou compreendesse os sentidos atribuídos e os discursos apropriados; a leitura e redação de texto quando a intenção era trabalhar a autoria e seminários. 


\section{A circulação de ideias e suas implicações para o ensino}

A sala de aula constitui-se como um importante espaço para a circulação de ideias, pois favorece a difusão científica e a compreensão do papel da ciência e da tecnologia no mundo contemporâneo. Consideramos que ela estimula a circulação intercoletiva, pois ocorre comunicação entre grupos que compõem círculos (C) distintos. Nos trabalhos 01AL, 04RE, 12CEd e 17CEn, observamos que a divulgação científica permeia diferentes grupos, como, por exemplo, nos que os alunos da graduação realizam seus estágios em turmas do ensino fundamental e/ou médio. A Figura 3 sinaliza o possível fluxo de informações e formação de coletivos de pensamento $(\mathrm{CP})$.

Figura 3 - Possível fluxo de circulação de ideias a partir do uso de TDC em sala de aula.

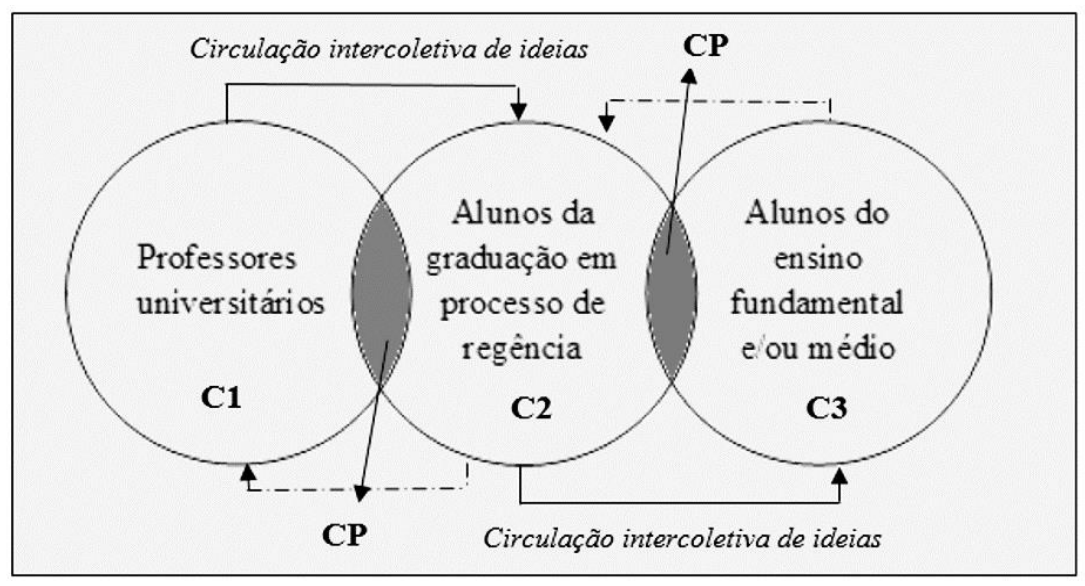

Fonte: Elaborado pelos autores, 2020.

Temos a existência de diferentes círculos, que se constituem como esotérico e exotérico um em relação ao outro. $\mathrm{O} C 1$ indica a presença de um círculo esotérico em relação a C2 e C3, sendo constituído por professores universitários que possuem conhecimento específico sobre Física, Química e Biologia e utilizaram ou discutiram TDC em suas aulas. O C2, composto por graduandos, constitui-se como esotérico em relação a C3. No processo de regência eles abordaram em suas aulas diferentes temáticas a partir de TDC, manchetes de jornais, vídeos, que contribuem para a veiculação de informações científicas e, por conseguinte, um ensino voltado à alfabetização científica.

Os professores, ao recorrerem à divulgação científica para desenvolverem suas aulas, podem influenciar deslocamentos de significados acerca de visões restritas relativas à natureza do conhecimento científico. Portanto, podem colaborar com a formação de coletivos de pensamento $(\mathrm{CP})$, que podem compartilhar de visões da ciência como uma construção coletiva, de suas implicações à sociedade e da necessidade de se informar para agir de forma consciente frente às situações-problemas características de um mundo globalizado e uma sociedade capitalista.

Nessa perspectiva, defendemos que a divulgação científica favorece a circulação de ideias, pois está entre suas funções contribuir com a formação da opinião pública e a compreensão de assuntos científicos. Neste sentido, os diferentes artigos analisados confirmam a diversidade de ideias circuladas em sala de aula, como: estudo de ondas e critérios para a escolha de um fone de ouvido, calorias e alimentos, combustível mais eficiente: etanol ou gasolina, o que um químico faz, educação em saúde, explorando hanseníase, anemia falciforme, 
automedicação e intoxicação alimentar. Temas que estão associados a situações de vivência, e sua compreensão estimula a mudança de hábito e o pensamento crítico.

\section{Nossas considerações}

O mapeamento que realizamos das produções acerca da divulgação científica compreendendo os anos de 2008 a 2018 indica um tímido crescimento na área. A investigação de Nascimento e Rezende Junior (2010) em periódicos semelhantes, no período de 1997 a 2007, localizou 36 artigos. Em contraponto, localizamos 59, o que representa um crescimento de $63 \%$. Isto pode estar relacionado ao número de instituições que passaram a ofertar cursos de licenciatura, como, por exemplo, os Institutos Federais, que oferecem hoje 669 cursos em 194 campi (CONIF, 2018), e a expansão de programas de Pós-Graduação em Educação/Ensino de Ciências.

A categoria "experiências em sala de aula" e "análise de jornais, revistas, programas de TV ou filmes" totalizou 40 trabalhos e indica a área de maior interesse dos pesquisadores, sendo os periódicos "Ciência e Educação" e "Alexandria" os de maiores representatividade nas publicações, respectivamente com 19 e 13 artigos. Enfim, ao considerar o número de propostas de divulgação científica desenvolvidas no espaço formal de ensino, percebemos a sala de aula como um contexto explorado e favorável para a circulação de ideias.

As pesquisas abordaram estratégias diversas, mas destacaram-se a leitura e uso de questionários/questões abertas para identificar as interpretações e sentidos atribuídos aos TDC. Os temas e conteúdos curriculares também variaram, mas ressaltamos a evidência da "Educação em Saúde", contemplada pelas discussões de doenças, meios de prevenção e tratamento. A revista "Ciência Hoje" foi uma das mais citadas pelos pesquisadores como fonte de extração dos TDC.

Por fim, defendemos que a divulgação científica precisa se fazer presente no espaço escolar desde a educação fundamental, nível em que ocorreu o menor número de intervenções, face ao seu potencial como interface para uma alfabetização científica. Sugerimos que os pesquisadores vinculados aos cursos de pós-graduação incentivem investigações na área, para que os formadores de professores utilizem dos recursos da divulgação científica em suas aulas, destacando o potencial diversificado de sua abordagem para a veiculação de informações e a apropriação de conhecimentos.

\section{Referências}

BARDIN, L. Análise de Conteúdo. Tradução Luis Antero Reto e Augusto Pinheiro. São Paulo: Edições 70, 2016.

BASTOS, M. H. C. A imprensa de educação e de ensino: repertórios analíticos. O exemplo da França. Revista Brasileira de Educação, v. 12, n. 34, p.166-168, 2007.

BUENO, W. C. Jornalismo Científico: conceitos e funções. Ciência e Cultura, v. 37, n. 9, p.1420-1427, 1985. Disponível em: https://biopibid.ccb.ufsc.br/files/2013/12/Jornalismocient\%C3\%ADfico-conceito-e-fun\%C3\%A7\%C3\%A3o.pdf. Acesso em: 30 ago. 2020.

CARNEIRO, M. H. S. Por que divulgar o conhecimento científico e tecnológico? Revista Virtual de Gestão e Iniciativas Sociais, edição especial, p. 29-33, 2009. 
CATANI, D. B. A imprensa periódica educacional: as revistas de ensino e o estudo de campo educacional. Educação e Filosofia, v.10, n. 20, p.115-130, 1996. Disponível em: http://www.seer.ufu.br/index.php/EducacaoFilosofia/article/view/928. Acesso em: 07 out. 2020.

CONIF, Conselho Nacional das Instituições da Rede Federal de Educação Profissional, Científica e Tecnológica. É 10 trabalhar no IF porque. Goiás: Instituto Federal Goiano, 2018.

COSTA, L. R. A ideologia e divulgação científica: uma análise baktiniana do discurso da revista Ciência Hoje. Baktiniana, v. 11, n. 2, p. 33-51, 2016. Disponível em: https://www.scielo.br/scielo.php?script=sci_arttext\&pid=S2176-45732016000200033. Acesso em: 15 jan. 2020.

FEHR, J. Fleck, sua vida e obra. In: Ludwik Fleck: estilos de pensamento na ciência. Belo Horizonte: Fino Traço, 2012.

FERREIRA, L. A Física Quântica: o estranho comportamento do mundo microscópico. In: NATALE, A. A.; VIEIRA, C. L. (Org.). O universo sem mistério: uma visão descomplicada da física contemporânea: do big bang às partículas. Rio de Janeiro: Vieira \& Lent, p. 153-179, 2003.

FERREIRA, L. N. A.; QUEIROZ, S. L. Artigos da revista Ciência Hoje como recurso didático no ensino de química. Química Nova, v. 34, n. 2, p.354-360, 2011. Disponível em: https://www.scielo.br/scielo.php?pid=S010040422011000200033\&script=sci_abstract\&tlng=es. Acesso em: 15 jan. 2020.

FERREIRA, L. N. A; QUEIROZ, S. L. Textos de Divulgação Científica no Ensino de Ciências: uma revisão. Alexandria: Revista de Educação em Ciências e Tecnologias, v. 5, n. 3, p. 101-126, 2012. Disponível em:

https://periodicos.ufsc.br/index.php/alexandria/article/view/37695. Acesso em: 05 mar. 2020.

FLICK, U. Introdução à pesquisa qualitativa. Tradução Joice Elias Costa. 3. ed. Porto Alegre: Artmed, 2009.

FLECK, L. Gênese e desenvolvimento de um fato científico. Tradução Georg Otte e Mariana Camilo de Oliveira. Belo Horizonte: Fabrefactum, 2010.

FREIRE, A. C. C. M.; MASSARANI, L. A cobertura de ciência para crianças: um estudo de caso em dois jornais científicos. Alexandria - Revista de Educação em Ciências e Tecnologias, v. 5, n. 1, p. 3-31, 2012. Disponível em: https://periodicos.ufsc.br/index.php/alexandria/article/view/37738. Acesso em: 05 mar. 2020.

GLEISER, M. A dança do universo. São Paulo: Companhia das letras, 1997.

GONÇALVES, F.P.; MARQUES, C. A. A circulação inter e intracoletiva de pesquisas e publicações acerca da experimentação no ensino de química. Revista Brasileira de Pesquisa em Educação em Ciências, v. 12, n.1, 2012. Disponível em: https://periodicos.ufmg.br/index.php/rbpec/article/view/4225. Acesso em: 18 jan. 2020. 
GOLDBACH, T.; EL-HANI, C. N. Entre receitas, Programas e Códigos: Metáforas e ideias sobre genes na divulgação científica e no contexto escolar. Alexandria: Revista de Educação em Ciências e Tecnologias, v.1, n.1, p. 153-189, 2008. Disponível em:

https://periodicos.ufsc.br/index.php/alexandria/article/view/37428. Acesso em: 10 mar. 2020.

GOMES, V. B.; SILVA, R. R.; MACHADO, P. F. L. Elaboração de textos de divulgação científica e sua avaliação por alunos da Licenciatura em Química. Química Nova na Escola, v. 38, n .4, p. 387-403, 2016. Disponível em: http://qnesc.sbq.org.br/online/qnesc38_4/15-CP20-15.pdf. Acesso em: 10 mar. 2020.

HEIDT, M. V. A Revista de Ensino do Estado do Rio Grande do Sul (1939-1942): um meio de divulgação das ideias do escolanovismo. In: JORNADA NACIONAL DE EDUCAÇÃO MATEMÁTICA E JORNADA REGIONAL DE EDUCAÇÃO MATEMÁTICA, 7. e 20., 2018, Passo Fundo. Anais [...]. Passo Fundo, 2018. Disponível em: http://perguntaserespostas.com.br/jem/images/Trabalhos2018/Eixo3/A-REVISTA-DOENSINO-DO-ESTADO-DO-RS-.pdf. Acesso em: 07 out. 2020.

LAMBACH, M. Atuação e formação de professores de Química na EJA: características dos Estilos de Pensamento - um olhar a partir de Fleck. 2007. Dissertação (Mestrado em Educação Científica e Tecnológica) - Universidade Federal de Santa Catarina, Florianópolis, 2007. Disponível em: https://repositorio.ufsc.br/handle/123456789/90651. Acesso em: 10 nov. 2019.

LAMBACH, M.; MARQUES, C. A. Estilos de Pensamento de professores de Química da educação de jovens e adultos (EJA) do Paraná em processo de formação permanente. Revista Ensaio, v. 16, n. 1, p. 85-100, 2014. Disponível em:

https://www.scielo.br/pdf/epec/v16n1/1983-2117-epec-16-01-00085.pdf. Acesso em: 08 mar. 2020.

LOWY, L. Fleck no seu tempo, Fleck no nosso tempo: Gênese e desenvolvimento de um pensamento. In: Ludwik Fleck: estilos de pensamento na ciência. Belo Horizonte: Fino Traço, 2012.

NASCIMENTO, T. G.; REZENDE JUNIOR, M. F. A produção sobre divulgação científica na área de educação em ciências: referenciais teóricos e principais temáticas. Investigações em Ensino de Ciências, v. 15, n. 1, p. 97-120, 2010. Disponível em: https://www.if.ufrgs.br/cref/ojs/index.php/ienci/article/view/317. Acesso em: 18 fev. 2020.

ORLANDI, E. P. A linguagem e seu funcionamento: as formas do discurso. São Paulo: Editora Brasiliense, 1983.

ORLANDI, E. P. Discurso e leitura. São Paulo: Cortez, 1988.

ORLANDI, E. P. Discurso, imaginário social e conhecimento. Em Aberto. Brasília, n. 61, p. 53-59, 1994. Disponível em:

http://rbep.inep.gov.br/ojs3/index.php/emaberto/article/view/2250. Acesso em: 08 out. 2020.

ORLANDI, E. P. Interpretação: autoria, leitura e efeitos do trabalho simbólico. 2. ed. Petrópolis, RJ: Vozes, 1996. 
ORLANDI, E. P. Paráfrase e Polissemia: a fluidez nos limites do simbólico. Rua, n. 4, p. 919, 1998. Disponível em:

https://periodicos.sbu.unicamp.br/ojs/index.php/rua/article/view/8640626/8177. Acesso em: 08 out. 2020.

ORLANDI, E. P. Análise do discurso: princípios \& procedimentos. Campinas, SP: Pontes, 2002.

ORLANDI, E. P. Análise do discurso: princípios \& procedimentos. 6. ed. Campinas, SP: Pontes, 2005.

ORLANDI, E. P. Discurso em análise: sujeito, sentido e ideologia. Campinas: Pontes, 2012.

PEREIRA, L. H. F. Os discursos sobre a matemática publicados na revista de ensino do Rio Grande do Sul (1951-1978). 2010. Tese (Doutorado em Educação) - Pontifícia Universidade Católica do Rio Grande do Sul, Porto Alegre, 2010.

PLANCK, M. Novas vias de acesso ao conhecimento da física. In: PLANCK, M.

Autobiografia científica e outros ensaios. Rio de Janeiro: Contraponto, 2012. p. 89-99.

PRYSBYCIEM, M. M. et al. Textos de Divulgação Científica: uma possibilidade para superar a fragmentação do conhecimento e as concepções de alunos de ensino médio em aulas de Química. Revista Brasileira de Ensino de Química, v. 10, n.1, p.70-78, 2015. Disponível em: http://qnesc.sbq.org.br/online/qnesc38_4/15-CP-20-15.pdf. Acesso em: 05 jan. 2020.

RIBEIRO, R. A.; KAWAMURA, M. R. D. Ciência em diferentes vozes: uma análise de textos de divulgação científica. In: ENCONTRO NACIONAL DE PESQUISA EM EDUCAÇÃO EM CIÊNCIAS, 5., 2005, Bauru. Anais [...]. Bauru: ABRAPEC, 2005. Disponível em: www.nutes.ufrj.br/abrapec/venpec/conteudo/artigos/3/doc/p803.doc. Acesso em: 15 jan. 2020.

RODRIGUES, E.; SILVA, M. J. C. A. A imprensa pedagógica representada pela Revista Brasileira de Educação: uma fonte de pesquisa para a história da educação. In: ANPED SUL, 10., 2014, Florianópolis. Anais [...]. Florianópolis: UDESC, 2014. Disponível em: http://xanpedsul.faed.udesc.br/arq_pdf/109-0.pdf. Acesso em: 07 out. 2020.

ROSA, P. R. S. Uma introdução o a pesquisa qualitativa em ensino de ciências. 2013. Disponível em:

http://www.paulorosa.docente.ufms.br/Uma_Introducao_Pesquisa_Qualitativa_Ensino_Cienci as.pdf. Acesso em: 20 mar. 2020.

SABBATINI, M. Alfabetização e Cultura Científica: conceitos convergentes? Ciência e Comunicação, v. 1, n. 1, 2004. Disponível em:

http://www.jornalismocientifico.com.br/revista/01/artigos/artigo5.asp. Acesso em: 05 mar. 2020.

SACKS, O. Tio Tungstênio: memórias de uma infância química. São Paulo: Companhia das Letras, 2002. 
SALÉM, S.; KAWAMURA, M. R. O texto de divulgação e o texto didático: conhecimentos diferentes. In: ENCONTRO DE PESQUISADORES EM ENSINO DE FÍSICA, 5., 1996, Belo Horizonte. Anais [...]. Belo Horizonte: SBF, 1996.

SOARES, F. A imprensa periódica educacional como fonte para a história da educação matemática do século XIX. In: SEMINÁRIO NACIONAL DE EDUCAÇÃO

MATEMÁTICA, 10., 2013, Campinas. Anais [...]. Campinas: UNICAMP, 2013. Disponível em: https://www.cle.unicamp.br/eprints/index.php/anais-snhm/article/view/84. Acesso em: 07 out. 2020 .

SOUZA. P. H. R.; ROCHA, M. B. Sistemática filogenética em Revistas de Divulgação Científica: Análises da Scientific American Brasil. Alexandria: Revista de Educação em Ciências e Tecnologias, v. 8, n. 1, p.75-99, 2015. Disponível em:

https://periodicos.ufsc.br/index.php/alexandria/article/view/1982-5153.2015v8n1p75. Acesso em: 05 abr. 2020.

STRATHERN, P. O sonho de Mendeleev: A verdadeira história da química. Rio de Janeiro: Jorge Zahar, 2002. Disponível em:

https://cfnplages.com.br/content/uploads/2020/05/Material-complentar-1\%C2\%AAs\%C3\%A9rie-Qu\%C3\%ADmica-O-sonho-de-Mendeleiev_-a-verdad-Paul-Strathern.pdf. Acesso em: 08 out. 2020.

TERRAZAN, E. A.; GABANA, M. Um estudo sobre o uso de atividade didática com texto de divulgação científica em aulas de física. In: ENCONTRO NACIONAL DE PESQUISA EM EDUCAÇÃO EM CIÊNCIAS, 4., 2003, Bauru. Anais [...]. Bauru: ABRAPEC, 2003.

Disponível em: http://fep.if.usp.br/ profis/arquivos/ivenpec/Arquivos/Orais/ORAL172.pdf. Acesso em: 05 mar. 2020.

VAN DIJK, T. A.; KINTSCH, W. Strategies of Discource Comprehension. Nova York: Academic Press.

ZAMBONI, L. M. S. Cientistas, jornalistas e a divulgação científica. Campinas: Autores Associados, 2001.

Recebido em agosto de 2020.

Aprovado em novembro de 2020. 